\title{
Ship Ballast Water Treatment
}

\author{
YURIY DACHEV, MIROSLAV TSVETKOV, VALENTIN ZLATEV \\ Navigation Department \\ Nikola Vaptsarov Naval Academy \\ 9000 Varna, 73, Vasil Drumev Str. \\ BULGARIA
}

\begin{abstract}
Ships use ballast water to ensure their buoyancy and stability. A significant amount of them is transported in various water basins of the World Ocean. Thus, together with ballast water, many microorganisms, phytoplankton and zooplankton are transported. The constant increase in the number of ships in the World Merchant Navy increases the risk of the spread of these invasive species in the local aquatic environment. This led to the decision of the International Maritime Organization (IMO) to legalize the control and treatment of ships' ballast water in order to minimize the risks of the spread of these invasive species.. Their transfer through ballast water to a new water environment is estimated as one of the 4 largest treats for the World Ocean. The International Convention for the Control and Management of Ballast Water and Sediments plays an essential role in the control of ballasting and de-ballasting processes. It regulates the D-1 and D-2 standards, as well as various ballast water treatment systems. Improving the possibility of subsequent change in the application of invasive species, the only way to solve this problem, is to fully prepare for ballast water and to develop alternative methods to ensure the buoyancy and resilience of ships.
\end{abstract}

Key words: ballast water, invasive species, control and management of ballast water and sediments

Received: June 12, 2020. Revised: January 7, 2021. Accepted: January 25, 2021. Published: February 7, 2021.

\section{General Information for the Ballast Waters \\ 1.1 The Importance of Ballast Waters}

The control over the stability of the ships is by using ballast water $(\mathrm{BW})$. There are three reasons for using BW [1]:

- Control of the stability of the ship during loading or unloading;

- Additional stability of the ship in bad weather conditions;

- Avoiding excessive loads on the ship's hull.

1.2 Basic Advantages of the Ballast Water

- Reducing of the stress to the hull of the ship and ensuring of transverse stability of the ship;

- Improving of propulsion power of the engine and ship;

- Improving of the maneuverability.

1.3 Consequences of the Use of Ballast Water

Although BW are essential for the safe operation of ships, there are many negative consequences affecting the environment and the species living in the water used for ballast. [2].

The water for filling ballast tanks is received from the sea. Thus, different types of marine fauna enter the tanks and bacteria, microbes, eggs, small invertebrates, cysts and larvae of different species are transported to the water basin, where the debalasting will take place. Once discharged into the other aquatic environment, if they survive, they multiply and increase their population in that area. Thus, they become an invasive species, competing with all native species. In many cases, they are a threat to the new environment.

Every year, about 10 billion tons of BW are transported to the world's oceans. About 7000 species of marine organisms are transported daily with BW. [3]

The first examples of alien transmission were recorded after the mass emergence of the Asian phytoplankton Odontella (Biddulphia sinensis) in the North Sea in 1903. In the late 1980s, Canada and Australia were among the first countries to have serious problems with invasive species of fauna.

\subsection{Economical Problems}

There are many economical problem involved with invasive species:

- Losses for the food industry due to reduced fishing and aquaculture production;

- Losses related to the overgrowth of ship hulls, floating signs and port infrastructure;

- Impact on recreation and tourism areas;

- Financial costs for the use of BW treatment systems on board the ship.

\subsection{Problems with Health}


The spread of invasive species today is considered one of the major threats to the ecological and economic condition of the planet. They cause serious damage to the Earth's biodiversity, on which humanity is highly dependent. People are used to the bacteria located in the areas where they live. [4] Due to BW, many bacteria that the human body is not accustomed to can affect it, causing digestive problems. Several cholera epidemics are directly linked to BW. An example of this is the epidemic, which started from 3 ports in Peru in 1991 and spread throughout South America. It affects more than one million and killed more than 10000 people in 1994. The strain has previously been found in Bangladesh alone.

\subsection{Expansion of the Problem with the Use of Ballast Water}

The annual growth of the world merchant fleet means higher fuel consumption, more pollution, higher levels of harmful emissions and increased use of BW. (Figure 1)

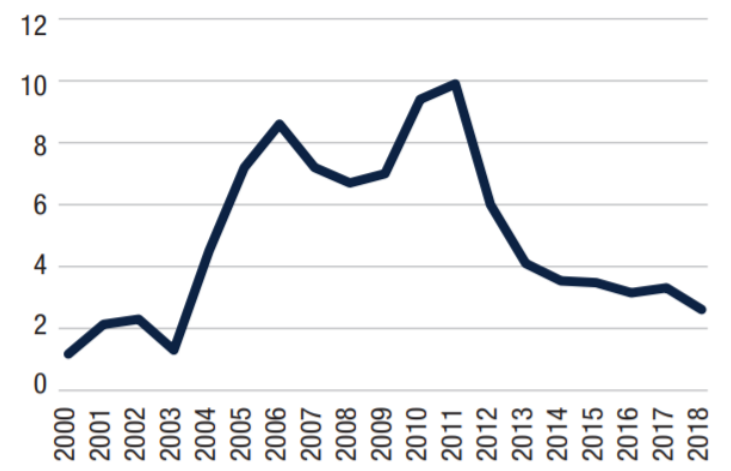

Figure 1 Growth of world merchant fleet for period 2000 - 2018 years (on \%).

\subsection{Examples for Invasion}

There are many cases of invasive species that have multiplied in an environment in which they have never been seen. Examples of the impact of these species on the local water environment and the damage they cause are, for example [5], [9]:

- North American crested jellyfish (Mnemiopsis leidyi). (Figure 2) This species first appeared in the 80s in the Black and Azov Seas. This is a species of jellyfish that reproduces rapidly (self-fertilizing hermaphrodite). It feeds on zooplankton, depleting its reserves and thus altering the food chain and ecosystem. Losses from the North American crested jellyfish in the local fishing industry are estimated at \$250 million a year.

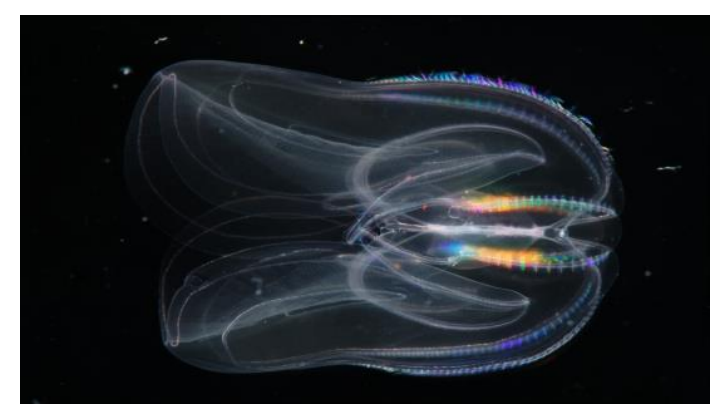

Figure 2 Crested jellyfish (Mnemiopsis leidyi)

- Strongil (Neogolus melanosromus) is a fish from the Black, Azov and Caspian Seas (Figure 3). Thanks to BW, the species are distributed in the Baltic Sea and around North America. A major problem with this invasive species is that it competes with other native species for the same food and habitat. [6]

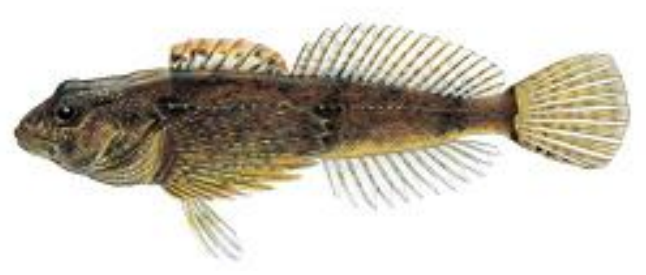

Figure 3 Strongil (Neogolus melanosromus)

- The zebra mussel (Dreissena polymorpha) is from the Black Sea. (Figure 4) The species is distributed in Western and Northern Europe and eastern North America. The Great Lakes (Canada) have suffered enormous damage through the overgrowth of industrial facilities, power plants, engine cooling systems and ship hulls. It blocks the inlet pipes of locks, irrigation and water supply systems. The economic damage in the United States alone amounted to between $\$ 750$ million and \$ 1 billion between 1989 and 2000 .

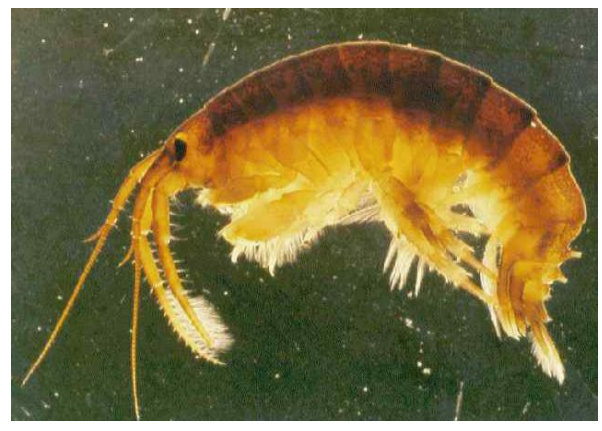

Figure 4 The zebra mussel (Dreissena polymorpha)

- The killer shrimp (Dikerogammarus villosus) has been found in the Great Lakes (USA) and 
Western Europe. It is the cause of the extinction of various native species such as shrimp and young fish. This species is from Eastern Europe, mainly from the Danube River. It has been found that it can survive at various temperatures, salinity and oxygen levels. This species is very aggressive in terms of colonization. Its migration was carried out thanks to BW from ships. [7]

\subsection{Geographical Risk}

Factors influencing the increase of invasive species are [8]:

- Concentration of the ships in the ports;

- Level of environmental similarity between the port of departure and the port of destination;

- Level of invasive species that already live in a certain region, provoking disturbance of the natural environment;

- Temperature and salinity of the water of destination of the BW.

The risk of invasion decreases when the characteristics are different and almost disappears when they are completely different. For example, the probability of spreading a species ballast in the Baltic Sea and debalast in the tropics is very low, as the probability of the species surviving is low.

In the Mediterranean, an invasive species is considered highly likely to spread if seawater has been ballast in the Black Sea, which has a similar environment and temperature. The average probability is considered when the water has been ballast from low temperatures - from the Baltic Sea and the Pacific coast. Low risk in the Mediterranean is considered when BW comes from the Arctic or Antarctica, as the temperature difference is large and organizes would die without the need for any treatment. The risk profile of the Mediterranean, which has a large number of pre-invasive species, following [8]:

- Ship's traffic is very high;

- There are many fish and mussel farms in the bays;

- Water quality is worse than a few years ago due to poor wastewater treatment and depletion of nutrients in seawater;

- Overfishing threatens the biodiversity of marine ecosystems.

\subsection{Factors Increasing the Impact of Ballast Water}

The impact of BW is caused by ships that have to control their stability when sailing or when loading/unloading cargo. There are other cases of ballasting or de-ballasting that lead to the spread of invasive species in local waters. These are [8]:

- Dredging vessels, which may be from different regions of the world, are involved in the construction of port facilities. When dredging, they must be de-balanced to improve their stability. In this process, they can discharge invasive species into the local water of the port;

- Increasing traffic in the port. This will increase the regions from which ships come, increasing the risk of new species coming from the ships' BW.

\section{Ballast Water Treatment Technologies}

BW treatment systems are very important for crews who must comply with the $\mathrm{BW}$ and Sediment Management Convention. There are many factors to consider when choosing a BWMS: crew safety and the environment, installation and maintenance costs, ease of use and installation, and space required for installation. [11]

There are various technologies used to purify BW: deoxidation, filtration systems, cavitation /ultrasound, chemical disinfection, ultraviolet rays, heat treatment, electro-mechanical separation, magnetic field treatment. Ships typically use 2 or more technologies to ensure that they meet the standards set by the IMO.

\subsection{Physical Separation or Filtration}

This technology does not use chemicals. The solids are separated by precipitation or filtration. Most of the particles can be separated from the $\mathrm{BW}$ and disposed of in the area where the $\mathrm{BW}$ is taken.

\subsubsection{Hydrocyclone}

It consists of a high-speed centrifuge that separates solids from water by centrifugal force. The main problem of the hydrocyclone is that it cannot separate the smallest organisms. [12]

\subsubsection{Filtration Nets}

They are used to remove solid particles that are scattered in the BW. They are an efficient system that does not use chemicals. There are fixed and mobile networks. The filter removes large solid particles from the water, but small organisms cannot be removed effectively.

\subsubsection{Filter Media}

It is effective in killing organisms smaller than $1 \mu \mathrm{m}$. Other physical methods can remove $50 \mu \mathrm{m}$ organisms. The crushed rubber (filter media) is recommended due to its small size. [12]

\subsubsection{Coagulation}

This is a technology used to remove the smallest particles that cannot be removed by filtration or hydrocyclone. The coagulation is used before the filtration process so as to fuse the small solids and form larger particles that are more easily separated from the BW by filtration or 
another physical method. The process of creating larger particles is known as flocculation, and large particles are called flocs.

Magnetite powder or sand is used to induce flocculation. Thanks to coagulation, the effectiveness of other physical methods increases. The disadvantage of this method is that it requires additional space on board due to the additional tank. [13]

\subsection{Magnetic Field Treatment}

Magnetic field treatment is applied after the coagulation process. Thanks to the magnetic powder used to create flocks, a magnetic force is applied to separate them from the water. The magnetic field is generated by magnetic disks.

\subsection{Purification of Ballast Water with Chemical Disinfection}

It consists of the use of chemicals to remove invasive species from the charged BW. Biocides that act as disinfectants are used to remove organisms. They are specially tested for marine organisms and their effectiveness is high. In addition, they are degradable and do not pose a danger to the environment, as they are not considered toxic substances. There are two types of biocides depending on its function:

\subsubsection{Oxidizing Biocides}

They are considered general disinfectants that destroy the cell membrane or nucleic acid of microorganisms. The most common types of oxidizing biocides are [14], [15]:

- Ozone. Once dissolved in water, it reacts with other chemicals and destroys organisms. The main disadvantage is that it is highly polluting and toxic;

- Chlorine. Once released into the BW, it kills microorganisms. Although chlorine is inexpensive, it is ineffective against cysts unless a concentration of at least $2 \mathrm{mg} / \mathrm{l}$ is used. This can irritate the human respiratory system, cause cancer and burn the skin in case of contact.

\subsubsection{Non-Oxidizing Biocides}

When dissolved in BW, they interfere with important organ functions such as reproduction and metabolism. They do not act immediately, so for good handling of BW it is necessary to apply at the beginning of the voyage. Because the process takes time, non-oxidizing biocides are not a good option for removing invasive species from $\mathrm{BW}$, especially if ships are sailing short distances. The main non-oxidizing biocide is glutaraldehyde, which is also used to sterilize medical equipment.

\subsection{Electric Pulse and Plasma Processing}

These technologies are considered environmentally friendly, inexpensive and easy to apply for the treatment of wastewater. They avoid the use of chemicals or other substances that may be hazardous to the environment. Electrical pulses are generated by two metal electrodes that generate high power current. [16], [17] For the plasma treatment, an impulse is generated which generates a plasma arc that kills the microorganisms living in the $\mathrm{BW}$.

The main disadvantages of both technologies are that they can affect the ship's operations, the staff must be trained and that the technologies are still being studied.

\subsection{Heat Treatment}

It raises the temperature of $\mathrm{BW}$ while the microorganisms are destroyed. The main advantages of the technology are that the ship's heating system can be used and that it is not necessary to use chemicals. The disadvantage is that the technology requires a lot of time and also causes corrosion in tanks. [18]

\subsection{Deoxygenation}

The idea of the technology is to reduce the level of oxygen in the BW so as to destroy microorganisms due to lack of oxygen. Nitrogen or various inert gases, which can achieve low oxygen levels, are most often used for this purpose. The advantage is that corrosion of the ballast tanks is avoided, increasing their useful life. The technology is environmentally friendly and economical. The disadvantage is that it lasts between two and four days. This is a slow method if emergency treatment of $\mathrm{BW}$ is required.

\subsection{Cavitation / Ultrasonic}

"Venturi" tubes or slotted plates are used to create cavitation bubbles. Their decay creates hydrodynamic forces, supersonic oscillations or high-frequency noises that tear the cell wall of organisms and kill them. For optimal efficiency, the technology must be combined with another. [11] No chemicals are used here and no additional installation is required.

\subsection{UV Rays}

Ultraviolet (UV) radiation is often used to sterilize drinking water, wastewater and purify aquaculture. It causes a photochemical reaction of biological parts such as nucleic acids (DNA and RNA) and proteins. Amalgam lamps surrounded by a quartz sleeve are used in the process. They can provide UV rays with different wavelengths and intensities depending on the specific need.

The technology is effective against many types of microorganisms, including viruses and cysts, relying on good conductivity of the rays through the water. This requires clean water and uncontaminated quartz sleeves. UV radiation is rarely used as a stand-alone processing technology. It is most often used in combination 
with a filter or hydrocyclone to remove larger organisms. A major drawback is the low conductivity in turbid water.

\section{Ballast Water Treatment Systems (BWTS)}

When choosing the type of BWTS for a given type of ship, many factors are taken into account that decide which system is most suitable for it. The ship must be studied individually in order to optimize the design of the BW treatment system and its installation. It is important to know in which ports the ship will operate. Some of them have specific requirements for BW. The water areas of the ports have different characteristics for salinity, temperature or turbidity. [10], [20], [21], [25]

An important factor is to know the size of the ship and how much it depends on ballast tanks to ensure its stability. Depending on the size and type of load, there may be BWTS that cannot be used because the pumping speed of the BW is low. This requires a lot of time to perform ballasting or de-ballasting, which is not economically viable. [19]

There are 4 factors to consider when choosing a BWTS [19]:

- Equipment: The cost of the equipment depends on the BW required for treatment.

- Project and design: The cost of design is usually related to the complexity of the installation. It is important where the system will be installed.

- Installation: Costs will be higher if there is not enough space for installation, which leads to the relocation of other equipment or change of use of some areas.

- Operation: Depending on the type of system installed, costs can be significantly reduced. For example, operating costs are those that are invested per $1000 \mathrm{~m}^{3}$ of purified BW. [20] They are directly related to energy (fuel) consumption. It is important to take into account both maintenance costs and a life cycle that takes into account how long the system will be used.

Although there are no official stages for the installation of BWTS on already built ships, it can be done in the following sequence:

- Research of the type of ship;

- Examination of the required amount of BW;

- Design of BWTS model;

- Installation;

- Check of the system.

The most used systems for treatment of BW are (Figure 5):

\subsection{UV System}

Approximately $31 \%$ of ships that are required to have a BW treatment system use UV systems. A filtration process (physical separation) is applied first, followed by ultraviolet irradiation to sterilize the ballast water. [22]

The systems are used for ships that do not require large amounts of BW (about $1000 \mathrm{~m}^{3}$ per hour). They are used for container vessels, Ro-Ro ships, general cargo, small bulk carriers, chemical tankers and ferries. [22] Their main advantages are that they are easy to install and maintain, work smoothly at different salinity levels and water temperatures, and are environmentally friendly.

The main disadvantage is that UV treatment has lower efficiency in turbid water. One of the most commonly used such systems is Wärtsilä AQUARIUS ${ }^{\circledR}$. [23]

\subsection{Electrolytic Chlorination Systems}

About $37 \%$ of ships that are required to have a BW treatment system use these systems. The first step is to perform filtration (physical separation), followed by electrolyte treatment. The systems are used for ships that need large volumes of BW. They are designed for ships that have a flow rate of about $8000 \mathrm{~m}^{3}$ of water per hour.

The advantages of these systems are the high efficiency for purification of large volumes of $\mathrm{BW}$, as the process is carried out inside the tanks. This is important for ships, as no additional space is required for BW handling. Disadvantages of these systems are that the efficiency decreases at low salinity levels and low BW temperatures. Installation, control and maintenance are more complex than UV systems. One of the most commonly used such systems is BalClor.

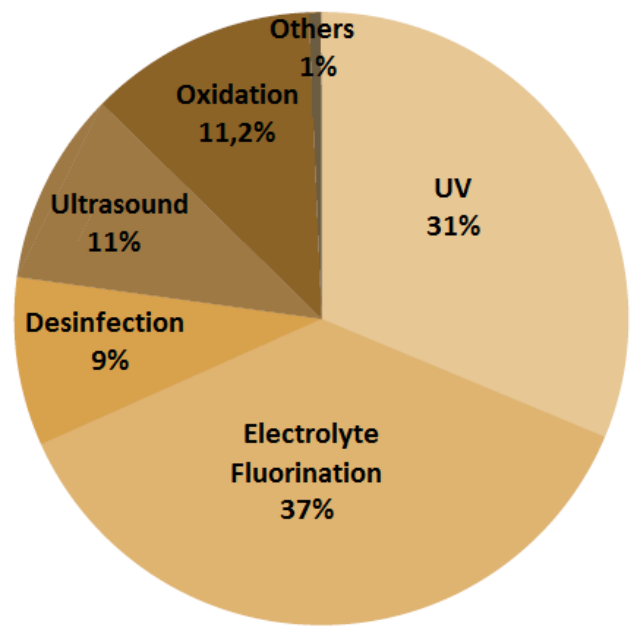

Figure 5 BWTS, used in the world merchant fleet

\subsection{Chemical Injection Systems}

A very small percentage of the merchant fleet uses these BW treatment systems. It is first 
filtered and then the chemical solution is injected into it. These systems are mainly used on large ships that have a ballast water flow rate of over 16 $000 \mathrm{~m}^{3}$ per hour. In addition, they are used for tanks that are ballast or de-ballast in local waters without any treatment.

The advantages of these systems are that they do not consume much energy and use less space than other installation systems. The disadvantages are that the chemicals used for the process can only be delivered to certain ports, stored on board in closed containers and the crew must be trained to work safely. One of the most commonly used such systems is JFE BallastAce. [24]

\section{Conclusion}

BW control is very important for the environment, human health and the economy. International organizations are aware of this and have taken the first step in implementing the BWM Convention.

There are various projects and researches that study how the impact of BW can be reduced. The aim is to achieve a minimal impact by improving the resilience of ships through the use of other systems or by improving the efficiency of ballast systems.

The GEF-UNDP-IMO partnership under the GloBallast program seeks to help many countries reduce the impact of $\mathrm{BW}$ through the implementation of the BWM Convention. The program has been implemented since 2007 by three important organizations: the Global Environment Facility (contributing to the project), the United Nations Development Program (responsible for implementation) and the International Maritime Organization (responsible for implementation). The aim is to set a timeframe for the implementation of the measures of the BWM Convention to ensure that the problem of BW is controlled worldwide. Initially, a period of 5 years (from October 2007 to October 2012) was set for the implementation of the BWM Convention, but was later extended until June 2017. Over the 10 years of the program, more than 100 countries have participated in the program. [26], [27]

Thanks to GloBallast, countries have been helped to improve national legislation and specialized training packages have been developed for port and ship management personnel.

The Instructions for Investment in BW Management Infrastructure is a document published by the IMO to provide guidance on where investment is needed to reduce the impact of BW. The study was funded by Royal Haskoning DHV and the European Bank for Reconstruction and Development (EBRD) in partnership with GloBallast.

The measures to be implemented by governments / international organizations depending on the funds invested are:

- Installation of facilities for receiving and discharging sediments from ballast tanks in ports;

- Establishment of a system for monitoring the biodiversity, which will improve the control of the local biological diversity;

- Proper cleaning of sediments from BW on board ships;

- Improving port state control with regard to BW. Ports and local authorities need to inspect the registers, take BW samples and be stricter when issuing the initial certificate or renewing the $\mathrm{BW}$ management plan;

- Public investments for research of alternative technologies for treatment of $\mathrm{BW}$, meeting the IMO standards;

- Reduction of data on vessels using alternative technologies.

The International Convention for the Control and Management of Ships' Ballast Water and Sediments, which entered into force in 2017, is a basic regulation for the control of ballasting and de-ballasting operations by ships worldwide. It plays an essential role in avoiding the spread of invasive species and in reducing the impact of ships on the local aquatic environment. Although the Convention can achieve a significant reduction in the impact of $\mathrm{BW}$, control by various bodies is needed to avoid abuses.

Processing technologies are one of the most important factors in reducing the impact of BW on the aquatic environment. BWMS have the role of properly handling BW to eliminate seawater organisms pumped into ballast tanks. There are many BW treatment systems, but the use of nonchemical based systems is the cleanest way to treat $\mathrm{BW}$, ensuring that it does not pollute the environment. For the correct control of the levels of the organisms it is necessary to use 2 or more systems, which in combination correctly perform the task of reducing the impact of BW.

Alternative projects to achieve ballast-free ships must play a special role in the near future. The realization of this type of ship will require large investments and efforts not only from shipping companies, but also from governments and international organizations. The use of alternative projects will lead to long-term cost savings. 
References:

[1] Jassal, R., Ballast Water Management Plan, [Published 13 October 2018], Available online: https://www.myseatime. com/blog/ detail/ballast-water-management

[2] Berger, J., Can the negative consequences of ballast water be prevented? Rotterdam, [Published 10 August 2017], Available online: http://www.bergermaritiem.nl/ negative consequences ballast water

[3] International Maritime Organization. Ballast water management convention, Montreal, Canada, 16-18 March 2016. Available online:

wwwcdn.imo.org > Documents > Proceedings RDForum6

[4] Kim, K., A study of the implications of the ballast water management convention for flag states, [Published 2013], Available online: https://www.semanticscholar.org/ paper/A-study-of-the-implications-of-theballast-water

[5] University of California, Organisms Found in Ballast Water. [Published 2020], Available online:http://ballast-outreach-ucsgep.ucdavis. edu/AIS_Info_and_Research/Organisms_ Found in Ballast Water/

[6] CABI, Neogobius melanostomus (round goby). [Published 18 November 2019], Available online: https://www.cabi. org/ isc/ datasheet/73163

[7] U.S. Fish\&Wildlife Service, Killer Shrimp (Dikerogammarus villosus). [Published 14 September 2017], Available online: https:// www.fws.gov/fisheries/ans/erss/highrisk/Dik erogammarus-villosus-ERSS-FINAL-Sept2017.pdf

[8] Challinor, S., Godwin, J., Davison, D., Cowdery, E.,Vercoe, J., Ballast Water Management Infrastructure Investment Guidance. [Published 6 March 2018], Available online: https://fdocuments.in/ document/ballast-water-managementinfrastructure-investment-ballast-watermanagement-infrastructure.html.

[9] OSPAR Commission, Ballast Water Exchange Areas in the North Sea. Portugal, 2014, [Published 23-27 June 2014], Available online: https://www.transportstyrelsen.se/ globalassets/global/sjofart/dokument/miljosk ydd/barlastvatten/intra_north_sea_ballastwat er exchange.pdf.

[10] Olofsson, M., Type-approved, USCGcompliant ballast water treatment systems now widely available. [Published 30 September 2019], Available online: https://www.dnvgl.com/expert-story/ maritime-impact/Ballast-water-managementtype-approved-USCG-compliant-treatmentsystems-now-widely-available.html

[11] Raunek, Marine Technology, How Ballast Water Treatment System Works, [Last updated of publication 4 January 2021], Available online: https://www.marineinsight. com/tech/how-ballast-water-treatmentsystem-works/.

[12] Kazumi, J., Ballast Water Treatment Technologies and Their Application for Vessels Entering the Great Lakes via the St. Lawrence Seaway. University of Miami, Florida, May 2007, Available online: http://onlinepubs.trb.org/onlinepubs/sr/sr291 kazumi.pdf.

[13] Mitsubishi Heavy Industries, Coagulation and Magnetic Separation Technology "Hitachi Ballast Water Purification. Tokyo, Japan, 7 April 2008, Available online: https://www.mhi.com/news/080407.html.

[14] Optimarin, Ballast Water Treatment: Chemical Disinfection (Oxidizing Biocides). Norway 2020, Available online: https://optimarin.com/

[15] Balaji R., Yaakob O., Emerging ballast water treatment technologies, Journal of Sustainability Science and Management, Volume 6, Number 1, June 2011, Pages 126138, Malaysia, ISSN: 1823-8556.

[16] European Commission, Using electric pulses to treat ballast water. [Published 2 April 2014], Available online: https://cordis. europa.eu/article/id/92643-using-electricpulses-to-treat-ballast-water

[17] European Commission, Final Report Summary - ECOSEASAFE. [Published 5 July 2013], Available online: https://cordis. europa.eu/project/id/262190/reporting

[18] Mesbahi, E., Norman, R., Quilez-Badia, G., Design of high-temperature thermal ballast water treatment system. Journal of Engineering for the Maritime Environment, 221(1), Pages 31-42, March 2007, DOI: 10.1243/14750902JEME39.

[19] Bacher, H., The Ballast Water Technology Retrofits Process, GREEN4SEA Athens Forum, 9 April 2014.

[20] SAFETY for SEA, Ten steps to selecting a ballast water treatment system. [Published 26 May 2011], Available online: https://safety 4sea.com/ten-steps-to-selecting-a-ballastwater-treatment-system/ 
[21] Šateikienè, D., Janutėnienè, J., Bogdevičius, M., Mickevičienè, R., Analysis into the selection of a ballast water treatment system. Journal for Transport, Vol. 30 No 2, Pages 145-151, Vilnius Tech Journals, 2015, DOI: https://doi.org/10.3846/16484142.2015.1045 025.

[22] Barthel, N., UV treatment of ballast water. Heraeus Noblelight 2020, Available online: https://www.heraeus.com/en/hng/contact her aeus_noblelight/Contact_form_hng.html

[23] Wärtsilä Corporation, UV Ballast water management system, Finland, 2019, Available online:

$\underline{\text { www.wartsila.com }>\text { docs }>\text { brochure-o- }}$ aquarius-uv

[24] Sunrio Marine Environment Engineering Co., Ltd., BalClor Ballast Water Management System, Qingdao, China, 2020, Available online: https://www.devex. com/ organizations/sunrui-marine-environmentengineering-company-ltd-116229.

[25] JFE Engineering Corporation, JFE Ballast Ace, Tokyo, Japan, 2017. Available online: https://jfe-ballast-ace.com/product/
[26] International Maritime Organization (IMO), The GloBallast Partnerships Project, London, June 2017. Available online: https://archive.iwlearn.net/globallast.imo.org/ the-globallast-partnerships-project-20072016/index.html

[27] Dimitrakiev, D., Gunes, E., Recent developments and trends in the chemical tanker market, International Journal of Scientific and Technology Research, 2019, Volume 8, Issue12, Pages 2075-2079.

[28] Liqun Liu, Bing Xu, Ocean Wireless Sensor Network Location Method, Based on Gradient Boosting Decision Tree, Engineering World, Pages 258-263, Volume 2, 2020, ISSN: 2692-5079.

Based on the project agreement „Cross border maritime spatial planning in the Black Sea Bulgaria and Romania, cod EASME/EMFF/ 2018/1.2.1.5/01/SI2.806725-MARSPLAN-BS II", financed by the European Commission, through Executive Agency for Small and Medium-sized Enterprises (EASME), from the European Maritime and Fisheries Fund (EMFF).

\section{Creative Commons Attribution License 4.0 (Attribution 4.0 International, CC BY 4.0)}

This article is published under the terms of the Creative Commons Attribution License 4.0

https://creativecommons.org/licenses/by/4.0/deed.en_US 